\title{
Senior registrar training in the psychiatry of old age in Scotland
}

\author{
Executive Committee of the Section for the Psychiatry of Old Age, Scottish Division of \\ the Royal College of Psychiatrists*
}

The psychiatry of old age has come to occupy an increasingly prominent role in psychiatry, because of demographic trends, and also because of service developments. About a third of referrals to most psychiatric services are for the over-65s and a high proportion of beds are occupied by this age group. Recently the training recommendations for senior registrars in the psychiatry of old age have been revised and clarified (Royal College of Psychiatrists, 1989) and old age psychiatry is now recognised as a specialty within psychiatry. Nevertheless there is continued concern about the training opportunities available in this field (Wattis, 1988), reports of difficulties in filling consultant posts, and evidence that the present guidelines for consultant staffing levels are inadequate (Ballinger et al, 1989). It has recently been recommended that one-third of senior registrar posts in general and old age psychiatry should be assigned to the psychiatry of old age (Sims, 1990).

The present survey concentrates on senior registrars in Scotland with an overall view of training, and also a survey of the opinions of individuals about the training, and career preferences.

\section{The study}

Senior registrar training in general and old age psychiatry in Scotland is based in Grampian, Lothian, Tayside and West Scotland. Forty-one posts were allocated to mental illness including the psychiatry of old age (Fleming \& Dodd, 1989) at the time of this survey, although this total excludes posts devoted mainly to psychotherapy, mental handicap, child psychiatry and forensic psychiatry. The organisers of the four training schemes were asked to identify the number of training attachments available for the psy-

*Brian R. Ballinger, Consultant Psychiatrist, Royal Dundee Liff Hospital, Dundee DD2 SNF; Jenny Eastwood, Consultant Psychiatrist, West Fife District General Hospital, Dunfermline; Grace Hodge, Consultant Psychiatrist, Dykebar Hospital, Paisley; Ronald Mcllwaine, Consultant Psychiatrist, Bellsdyke Hospital, Larbert; Paul Morrison, Consultant Psychiatrist, Royal Edinburgh Hospital, Edinburgh; J. Barrie Murphy, Consultant Psychiatrist, Gartnavel Royal Hospital, Glasgow; Peter Olley, Consultant Psychiatrist, Royal Cornhill Hospital, Aberdeen and Andre L. Phanjoo, Consultant Psychiatrist, Roya Edinburgh Hospital, Edinburgh. chiatry of old age, either in full-time or more substantial part-time posts. They were also asked to provide details of occupants of these training slots during the previous five years and also of the present posts held by these previous trainees. The number of consultant posts in old age psychiatry advertised in the previous three years in the British Medical Journal was reviewed, excluding re-advertisements within the same year.

All senior registrars in post in December 1989 were asked to fill in a standard questionnaire, giving details of their experience in psychiatry and in particular the psychiatry of old age and also the amount of old age psychiatry training expected during their senior registrar time. They were asked to indicate their career preferences, particularly with regard to old age psychiatry, and to give their views on the advantages and disadvantages of working in this field.

\section{Findings \\ Trainers' responses}

The four Scottish centres offered six training placements in the psychiatry of old age comprising two each in Tayside, Lothian and West Scotland, although not all of these were occupied all the time. In the five years before the survey was carried out, 18 trainees had received training in old age psychiatry, half for six months and half for approximately one year. Of these 18 senior registrars, seven were still trainees at the time of the survey. Of the 11 who had achieved consultant status, five are in appointments involving five or more sessions of old age psychiatry and the other six hold general psychiatry posts. During 1987-89 an average of six consultant posts per year were advertised in old age psychiatry in Scotland, including joint appointments with general psychiatry and part-time posts.

\section{Trainees' responses}

Of the 41 senior registrar posts in Scotland (excluding child psychiatry, mental handicap, psychotherapy and forensic psychiatry), 38 were occupied at the time of the survey. Responses were obtained from 31 trainees, six in Grampian, seven in Tayside, eight in Lothian and ten in West Scotland. Of these five $(16.1 \%)$ indicated a definite intention to follow a 
career in old age psychiatry, two on a full-time basis and three as "joint appointments" with general psychiatry, with $50-70 \%$ of the time devoted to old age psychiatry. Five other trainees indicated a possible interest in a career in old age psychiatry, with two of these expressing a definite wish for sessions in this field. Twenty-one senior registrars had no interest in a career in this specialty. Other career intentions included general psychiatry (27), forensic psychiatry (5), addictions (4), psychotherapy (2), mental handicap (1), some indicating more than one interest. These figures exclude trainees in specialist senior registrar posts in psychotherapy, mental handicap, child psychiatry, and forensic psychiatry.

Of the 31 responders, 18 were female and the mean age was 32.7 years (range 29-43) with an average of 6 years 9 months experience in psychiatry and 2 years 2 months as senior registrar. The five definitely aiming for old age psychiatry had a mean age of 35 years 2 months with an average of 6 years 9 months in psychiatry and only 9 months in a senior registrar post. Of those responding, 27 had had at least 6 months full-time registrar experience in old age psychiatry and three others had part-time experience with only one having had no experience at all.

Only six senior registrars reported old age psychiatry experience at senior registrar level at the date of the survey with a mean duration of only two months. Fourteen, however, expected to have an attachment to old age psychiatry (including the six above), four expecting 6 months, eight 1 year and two 2 years. Six also expected to have some experience in geriatric medicine as a senior registrar.

When asked about the advantages of working in the psychiatry of old age, the following were mentioned: clinical interest (10), community work (10), importance of this expanding field (7), good promotion prospects (4), multidisciplinary work (4), service organisation experience (4), experience with physical illness (4), liaison work (3) and research opportunities (1). Some cited more than one advantage and five could see no advantages at all. The disadvantages of old age psychiatry work reported were lack of resources (13), too much emphasis on dementia (8), lack of variety (3), personal stress and work-load (3), problems in defining the psychiatrists' role (2), problems dealing with physical illness (2), organisational difficulties (1) and diagnostic problems (1).

\section{Comment}

There has been concern in Scotland and elsewhere about the problems of recruitment into old age psychiatry, particularly in view of the importance of this expanding field. Surveys in this specialty were made difficult by the previous lack of separate identification of the psychiatry of old age in manpower statistics. The numbers in this report were relatively small and there were some non-responders but the findings indicate some cause for concern.

The expected output from senior registrar grades is approximately nine per annum in Scotland (for general and old age psychiatry) (Fleming \& Dodd, 1989). The estimate that the psychiatry of old age represents around a third of psychiatric work would indicate need for at least three full-time equivalents of old age psychiatry consultants to be trained per annum in Scotland. This, however, is likely to be an underestimate because of joint appointments, which could double the requirement, and because of the need for expansion to meet demographic trends. The number of advertised posts would point to a higher requirement of about six appointments per annum, although some of these were likely to be readvertisements.

Six training placements would have been sufficient to meet this need with the former requirements, although they have not been utilised continuously. However, the new requirement for two years training in old age psychiatry for specialists and special responsibility posts is likely to mean that this number of placements is inadequate, particularly as some trainees will be seeking "joint appointments" and because of the requirement to meet the needs of general psychiatrists for training in the psychiatry of old age. There is also the urgent need to increase the number of old age psychiatrists (Ballinger et al, 1989).

The number of trainees opting for old age psychiatry in Scotland appeared to be inadequate, particularly in view of the wish of some to seek joint appointments, unless at least all of those with "possible" career intentions can be tempted into this field. It is possible that the non-responders in this survey included intending old age psychiatrists but informal enquiries make this possibility relatively unlikely.

There is therefore an urgent need to increase the training opportunities and enhance the attractiveness of the psychiatry of old age. The statement from the College on senior registrar numbers (Sims, 1990) is likely to be a helpful step in the right direction.

\section{References}

Ballinger, B. R., Craig, R. J., Eastwood, J., Hodge, G., McIllwaine, R., Murphy, J. B. \& Phanjoo, A. L. (1989) Geriatric psychiatry manpower - seven services in Scotland. Health Bulletin, 47, 282-287.

FLEMING, C. F. \& DODD, W. (1989) Medical staffing in the National Health Service in Scotland and junior hospital doctors' promotion prospects in a time of change. Health Bulletin, 47, 242-257.

JCHPT (1989) Higher training in old age psychiatry. Psychiatric Bulletin, 13, 652.

Sims, A. C. P. (1990) Senior registrar numbers in general psychiatry and old age psychiatry. Psychiatric Bulletin. $14,696$.

WATTLS, J. P. (1988) Senior registrar training in old age psychiatry in the United Kingdom. Bulletin of the Royal College of Psychiatrists, 12, 233-234. 